Article

\title{
Instability of Mixed Nash Equilibria in Generalised Hawk-Dove Game: A Project Conflict Management Scenario
}

\author{
Sheryl Le Chang * and Mikhail Prokopenko \\ Complex Systems Research Group, Faculty of Engineering and IT, University of Sydney, NSW 2006, Australia; \\ mikhail.prokopenko@sydney.edu.au \\ * Correspondence: le.chang@sydney.edu.au
}

Received: 4 September 2017; Accepted: 21 September 2017; Published: 2 October 2017

\begin{abstract}
This paper generalises the Hawk-Dove evolutionary game by introducing cost sharing ratios for both players, and applies the generalised Hawk-Dove model to conflict management in projects through investigating the stability of Nash equilibria. A model with clashing interests between a project owner and a contractor is considered to derive their strategy adaptation given the cost sharing ratios. As expected, the pure Nash equilibria are shown to be dominantly stable while the mixed strategy equilibrium is observed to be unstable, across the range of considered cost sharing ratios. In addition, simulations are conducted on the strategy adaptation and stability of the equilibria under noisy and latent conditions. The obtained results can be used by project managers in optimising their strategy in practice.
\end{abstract}

Keywords: evolutionary game theory; project conflict management; Nash equilibrium; Hawk-Dove game

\section{Introduction}

Project management emerged in the 1950s and expanded its applications in an increasing number of industries. According to the guide to the Project Management Body of Knowledge (PMBOK Guide 5th edition) [1], a project is a "temporary endeavour undertaken to create a unique product, service, or result". The delivery of a project usually involves a wide range of stakeholders, among which the project owner and contractor (also known as the supplier) are arguably the most important players.

There are two well-known challenges in the owner-contractor management [2]:

- The divergence of interests may induce conflict, which in return can lead to greater risk and lengthened project duration.

- The participants' behaviour is often tacit, requiring clarifications which may be obtained through rigorous modelling.

These challenges underlie possible conflicts and disputes, which may not only cause damage to the project owner and the contractor, but also may directly impair the outcome of projects. Having a relatively low-cost negotiation is the most popular resolution to settle disputes in comparison with other alternatives, such as partnering, arbitration, and dispute review boards [3]. Therefore, modelling negotiation as a way to settle conflicts between the project owner and the contractor has attracted research interest. While earlier studies concentrate on developing a framework or tactic for the negotiating parties, the more contemporary research incorporates game theory to obtain the optimal outcome. Game theory may offer solutions to the problem by providing quantitative models of conflict and co-operation between intelligent, rational decision-makers [4]. It also suggests insights on how 
one's decision will influence that of another and thus can be used to resolve conflicts and optimise risk handling between stakeholders in project management. By using game theory, project managers could reduce the chances of conflicts and gain better control in managing the owner-contractor liaison [5]. A number of studies have employed game theory in specific project settings in recent years, by focusing on the negotiation between the government and the private funding parties in Public-Private Partnership projects [6-8], and/or over some particular types of contracts, such as the BOT (Build-Operate-Transfer) contracts $[9,10]$. However, project management is known to be a broad discipline and the practitioners are keen to obtain a holistic and pluralistic understanding of stakeholder engagement [2]. It is therefore of interest to establish game theory as a means to provide a generalised negotiation model that can fit into different project environments.

This paper investigates the feasibility of utilising the evolutionary game theory in project management by setting up a representative model of a conflict between the owner and the contractor. The game is set in the context of the classical Hawk-Dove game, and the stability of Nash equilibria is studied through both analytical derivations and computational simulations. In doing so, the well-known Hawk-Dove evolutionary game is generalised by introducing cost sharing ratios for both players. Follow-up analysis is conducted by analysing the adaptation of optimal strategies and stability of the resultant equilibria under noisy and latent conditions which are typical in practical scenarios.

\section{Evolutionary Game Theory: Generalised Hawk-Dove Model}

The Hawk-Dove game originally developed by Maynard Smith [11] is one of the well-recognised standard paradigms of evolutionary game theory. It draws inspiration from the biology and models two players, hawk and dove, engaging in a single symmetric contest over a resource [12]. The payoff matrix for the Hawk-Dove game includes the value of the contested resource $v$, and the cost of an escalated fight $c$ (Table 1). It is almost always assumed that the value of the resource is less than the cost of a fight, i.e., $c>v>0$ [11]. The cost of fight only incurs if a hawk confronts another hawk, producing the resultant payoff for each player as $\frac{v-c}{2}$. When a dove meets another dove, however, no fight will engage and they share the resource equally, each with payoff $\frac{v}{2}$. The payoffs for a hawk encountering a dove reflect the discrepancy of the fighting ability for the two species so that the hawk receives the resource $v$ in full while the dove has nothing.

Table 1. Classical (canonical) Hawk-Dove game.

\begin{tabular}{ccc}
\hline $\begin{array}{c}\text { Player 1 } \\
\text { Player 2 }\end{array}$ & Hawk & Dove \\
\hline Hawk & $\left(\frac{v-c}{2}, \frac{v-c}{2}\right)$ & $(v, 0)$ \\
\hline Dove & $(0, v)$ & $\left(\frac{v}{2}, \frac{v}{2}\right)$ \\
\hline
\end{tabular}

An evolutionarily stable strategy (ESS) is a strategy such that if all members of a population adopt the ESS then no other strategy can replace it. The concept of ESS is the refinement of a Nash equilibrium, a stable strategy where a player gains no benefit from changing to a different strategy. In the classical two-player Hawk-Dove model, there are typically three Nash equilibria: two appear as a pure strategy and one as a mixed strategy [13]. The classical Hawk-Dove game is a symmetric contest where the cost of confrontation is equally shared; and the resultant ESS is a mixed strategy in the sense that "the population will be genetically polymorphic or individuals will be behaviourally variable" [14]. Later studies extended the consideration of contests to a two-stage game where the contest repeats twice [15], and more importantly, to an asymmetric form in terms of the role dominance, 
unequal payoffs [14] and payoff relevance where differences in the value of winning were introduced for different players [16]. The ESS in asymmetric contests usually appears to avoid an escalation of the confrontation [14]. This conclusion also holds if the players are allowed to communicate prior to the game, e.g., if they are allowed to threaten each other before choosing their moves [17]. The modern applications of the Hawk-Dove game include the bargaining and negotiation processes. If the Hawk-Dove game is multi-stage while the two players play the game in order (i.e., the second player moves after knowing the first player's strategy), the equilibrium covers a fully cooperative case when both players act as doves in both symmetric and asymmetric settings, together with multiple asymmetric equilibria [18]. The interaction has also been extended to allow the players to confirm the proposed strategy before committing to a Hawk-Dove agreement [19]. These applications in the negotiation process, however, assume that no pre-established positions are held before bargaining. This assumption, unfortunately, does not hold in the scenario of project conflicts because the inherent role of the project participants is to decide their positions in the negotiation process, and so they are not likely to cooperate willingly acting as doves. Informally, the optimal results for the players' individual interests emerge when two parties deliberately choose the opposite ("confrontational") strategies [20].

The interaction between two players in a contract-based project management setting involving the owner and the contractor are often modelled using the single-stage Hawk-Dove model with modified asymmetric payoff matrix [21,22]. This selection of player roles is representative of resource-sharing in project management, and this context can be easily modified to represent other stakeholders given that the decision-making involves negotiation over some resource. Two strategies are, therefore, available in this model for the project participants, representing the hawk (aggressive) and the dove (acquiescent), as summarised in Table 2, mapping to the classical form. By pairing the strategies, four scenarios are available: $\left(A_{1}, B_{1}\right),\left(A_{1}, B_{2}\right),\left(A_{2}, B_{1}\right)$ and $\left(A_{2}, B_{2}\right)$. The matrix elements are modified to reflect two traits in the negotiation of the tendering process:

- The owner has a higher power and assumes the governance of the project.

- The owner pays an agreed amount to the contractor.

The project owner makes an offer at a price for some work to be carried out, represented with a negative sign of the corresponding payoff; the project contractor, on the other hand, accepts the quote, making gains shown with a positive sign. The project owner naturally has higher governance over the project and therefore is not penalised for taking a strong stance opting for strategy $A_{1}$, whereas the project contractor would incur some additional cost when he/she decides to initiate negotiation by choosing strategy $B_{1}$. The cost of negotiation, however, is most definitely not shared equally, as is the case considered in the classical Hawk-Dove game; instead, the fraction that each player needs to bear varies in accordance to his/her attitude towards risks.

Table 2. Hawk-Dove strategy representation in a project conflict.

\begin{tabular}{|c|c|c|}
\hline $\begin{array}{ll}\text { Project Contractor } & \text { Project Owner } \\
\end{array}$ & Hawk $A_{1}$ & Dove $A_{2}$ \\
\hline Hawk $B_{1}$ & $\left(\frac{v-c}{2},-\frac{v-c}{2}\right)$ & $(v,-v)$ \\
\hline Dove $B_{2}$ & $(v,-v)$ & $\left(\frac{v}{2},-\frac{v}{2}\right)$ \\
\hline
\end{tabular}

Noting the above mentioned two traits, the payoff matrix of the Hawk-Dove model constructed for the project management setting is refined by:

- A hawk owner does not incur an additional cost but a hawk contractor would. The cost of negotiation varies with the attitude of the two parties.

- Owner's payoff is represented as a (negative) "loss" (constituting the payment amount), while the contractor payoff, conversely, is positive and includes the received payment amount. 
In a realistic project conflict scenario, however, it should be expected that even when facing a hawk contractor, a dove owner should pay an agreed amount subject to some additional costs. This can be modelled, in our generalisation of the Hawk-Dove payoff matrix, by introducing a distinction between agreed payment amounts $V$ (owner as a hawk) and $D$ (owner as a dove), while also including different (cost sharing) penalty components $L_{1}$ and $L_{2}$.

Formally, four parameters, $V_{1}, V_{2}, D_{1}, D_{2}$, are used to represent initial contracted payments in four scenarios $\left(A_{1}, B_{1}\right),\left(A_{1}, B_{2}\right),\left(A_{2}, B_{1}\right)$, and $\left(A_{2}, B_{2}\right)$ respectively, as shown in Table 3 , extending the study of [21]. In cases of $\left(A_{1}, B_{1}\right)$ and $\left(A_{2}, B_{1}\right)$, when the contractor acts as a hawk $\left(B_{1}\right)$, the additional costs may be incurred, for instance, from communication and contract negotiation. These costs are represented by $L_{1}$ if the project owner also acts as a hawk, and $L_{2}$ if the owner steps down as a dove. The introduction of sharing ratios, $\alpha$ and $\beta$ that range from 0 to 1 , decides how the penalties are distributed between the two parties. In $\left(A_{1}, B_{1}\right)$, the owner's portion of $L_{1}$ is $\alpha L_{1}$ and the contractor's one is $(1-\alpha) L_{1}$; similarly, in $A_{2} B_{1}$, the owner's share of $L_{2}$ is $\beta L_{2}$ and the contractor's one is $(1-\beta) L_{2}$, resulting in the payoff matrix shown in Table 3.

Table 3. Generalised payoff matrix: Owner-Contractor.

\begin{tabular}{ccc}
\hline \hline Project Owner & $A_{\mathbf{1}}$ & $\boldsymbol{A}_{\mathbf{2}}$ \\
\hline$B_{1}$ & $\left(V_{1}-(1-\alpha) L_{1},-V_{1}-\alpha L_{1}\right)$ & $\left(D_{1}-(1-\beta) L_{2},-D_{1}-\beta L_{2}\right)$ \\
\hline$B_{2}$ & $\left(V_{2},-V_{2}\right)$ & $\left(D_{2},-D_{2}\right)$ \\
\hline
\end{tabular}

An assumption holds that the payment amount (i.e., resource) varies with both players' attitude. The project owner, by nature, is more dominant in shaping the contract terms; therefore, if the owner "steps down" by acting dovish, the contractor who compromises (i.e., acting dovish too) receives a higher contract amount than those who stay rigid and aggressive. In cases where the owner is acting as a hawk, a more demanding hawk contractor would get paid more. The confrontation between the hawk owner and the hawk contractor surely requires a longer time to resolve the dispute, translating to the higher incurred additional cost. These conditions are expressed in constraints (1).

$$
\left\{\begin{array}{l}
V_{1}>V_{2}, D_{1}>D_{2} \\
D_{1}>V_{1}, D_{2}>V_{2} \\
L_{1}>L_{2}
\end{array}\right.
$$

To ensure that in the generalised Hawk-Dove game the best outcome for the owner and for the contractor still occur in scenarios $\left(A_{1}, B_{2}\right)$ and $\left(A_{2}, B_{1}\right)$, further constraints are needed:

$$
\left\{\begin{array}{l}
\beta L_{2}-\alpha L_{1}<V_{1}-D_{1} \\
\beta>1-\frac{D_{1}-D_{2}}{L_{2}} \\
\alpha<1-\frac{V_{1}-V_{2}}{L_{1}}
\end{array}\right.
$$

These constraints set the conditions capturing the scenarios in which the opposing strategies, $\left(A_{1}, B_{2}\right)$ and $\left(A_{2}, B_{1}\right)$, are the optimal cases for the project owner and the project contractor respectively. This is consistent with the canonical Hawk-Dove game where the Hawk-Dove pair is always the most advantageous for the hawk player. By applying the conditions, when the project owner is using strategy $A_{1}$ acting as a hawk, the project contractor has a tendency to move from $B_{1}$ being a hawk to $B_{2}$ being a dove, and vice versa. It is a common practice in the negotiation process known as the "strategic and pragmatic approach" where both parties accept the adjustment to the original plan and is believed to be the preferred method for producing cost effective outcomes [23]. Mathematically, Equation (2) 
set an upper boundary $\alpha_{\max }$ for $\alpha$ and a lower bound $\beta_{\min }$ for $\beta$ so that when the contractor acts as a hawk $\left(B_{1}\right)$, there is a maximum cap $\alpha_{\max }$ for the project owner to absorb $L_{1}$ if he/she plays strategy $A_{1}$; if the project owner decides on strategy $A_{2}$, the compromise is reflected by sharing at least $\beta_{\min } L_{2}$.

In $\left(A_{2}, B_{1}\right)$, when $\beta$ equals to 1 , the owner absorbs all additional costs with the contractor being damage-free. This case evidently resembles the original Hawk-Dove model as the payoff clearly favours the hawk contractor: having no loss from the confrontation. Conversely, when $\beta$ slides to 0 , the payoff favours the dove owner while the hawk contractor pays the heavy toll for their aggression by absorbing all the additional cost and the game is no longer a Hawk-Dove game.

\section{Analytical Solutions}

Let us set the expected probability of owner taking strategy $A_{1}$ as $q$, and the expected probability of owner taking strategy $A_{2}$ holds as $(1-q)$. Similarly, the expected probabilities of the contractor adapting strategy $B_{1}$ and $B_{2}$ are $p$ and $(1-p)$ respectively. The partial expected revenue, $U_{A 1}$ and $U_{A 2}$ for owner, and $U_{B 1}$ and $U_{B 2}$, for contractor, correspond to the revenue generated from carrying out strategy as hawk or dove, given the mixed strategy of the opponent, expressed as follows:

$$
\left\{\begin{array}{l}
U_{A_{1}}=\left(-V_{1}-\alpha L_{1}\right) p-V_{2}(1-p) \\
U_{A_{2}}=\left(-D_{1}-\beta L_{2}\right) p-D_{2}(1-p)
\end{array}\right.
$$

The total expected revenue for the owner, $U_{A}$, is thus derived as:

$$
U_{A}=U_{A_{1}} q+U_{A_{2}}(1-q)
$$

Expected partial revenue for the contractor follows the same mechanism and can be written as:

$$
\left\{\begin{array}{l}
U_{B_{1}}=\left[V_{1}-(1-\alpha) L_{1}\right] q+\left[D_{1}-(1-\beta) L_{2}\right](1-q) \\
U_{B_{2}}=V_{2} q+D_{2}(1-q)
\end{array}\right.
$$

Therefore, the total expected revenue for the contractor, $U_{B}$, is obtained as:

$$
U_{B}=U_{B_{1}} p+U_{B_{2}}(1-p)
$$

As pointed out by $[21,24]$, the replicator equation shows the growth rate of a strategy, which describes the selection process where the more successful strategy spreads until it becomes dynamically stable. In other words, the strategy keeps adapting if the strategy's payoff results in a higher payoff. Hence, the replicator equation (i.e., growth rate) of the contractor acting as a hawk is:

$$
\begin{aligned}
& \frac{d p}{d t}=p\left(U_{B_{1}}-U_{B}\right) \\
& \frac{d p}{d t}=p(1-p)\left[\left(V_{1}-V_{2}+D_{2}-D_{1}+(1-\beta) L_{2}-(1-\alpha) L_{1}\right) q+D_{1}-D_{2}-(1-\beta) L_{2}\right]
\end{aligned}
$$

Analogously, the growth rate of the owner acting hawk is:

$$
\begin{aligned}
& \frac{d q}{d t}=q\left(U_{A_{1}}-U_{A}\right) \\
& \frac{d q}{d t}=q(q-1)\left[\left(V_{1}-V_{2}+D_{2}-D_{1}+\alpha L_{1}-\beta L_{2}\right) p+V_{2}-D_{2}\right]
\end{aligned}
$$

By solving the differential equations, the equilibrium points are obtained as:

$$
\left\{\begin{array}{l}
p(1-p)\left(M_{p} q-N_{p}\right)=0 \\
q(q-1)\left(M_{q} p-N_{q}\right)=0
\end{array}\right.
$$


where

$$
\left\{\begin{array}{l}
M_{p}=V_{1}-V_{2}+D_{2}-D_{1}+(1-\beta) L_{2}-(1-\alpha) L_{1} \\
N_{p}=D_{1}-\beta L_{2}-(1-\beta) L_{2} \\
M_{q}=V_{1}-V_{2}+D_{2}-D_{1}+\alpha L_{1}-\beta L_{2} \\
N_{q}=V_{2}-D_{2}
\end{array}\right.
$$

From Equation (7), $p$ and $q$ can be obtained as constant roots $p_{0}, p_{1}, q_{0}, q_{1}$, as well as a parameter-dependent root pair $p^{*}$ and $q^{*}$, yielding:

$$
\left\{\begin{array} { l } 
{ p _ { 0 } = 0 } \\
{ p _ { 1 } = 1 } \\
{ p ^ { * } = \frac { N _ { q } } { M _ { q } } }
\end{array} \quad \left\{\begin{array}{l}
q_{0}=0 \\
q_{1}=1 \\
q^{*}=\frac{N_{p}}{M_{p}}
\end{array}\right.\right.
$$

The solutions $p^{*}$ and $q^{*}$ can be written in terms of the payment variables and cost sharing ratios:

$$
\left\{\begin{array}{l}
p^{*}=\frac{D_{2}-V_{2}}{V_{1}-V_{2}+D_{2}-D_{1}+\alpha L_{1}-\beta L_{2}} \\
q^{*}=\frac{D_{2}-D_{1}+(1-\beta) L_{2}}{V_{1}-V_{2}+D_{2}-D_{1}+(1-\beta) L_{2}-(1-\alpha) L_{1}}
\end{array}\right.
$$

When $p$ and $q$ take constant roots $p_{0}, p_{1}, q_{0}, q_{1}$, their combinations form the equilibrium points $(0,0),(0,1),(1,0)$ and $(1,1)$, each of which corresponds to scenario $\left(A_{2}, B_{2}\right),\left(A_{1}, B_{2}\right),\left(A_{2}, B_{1}\right)$ and $\left(A_{1}, B_{1}\right)$. Pure and stable Nash equilibria are found at combinations $(0,1),(1,0)$ [25]. When $p^{*}$ and $q^{*}$ are taken, the equilibrium shifts to the unstable mixed strategy where the choice of strategy is dependent on $\alpha$ and $\beta$.

\section{Results}

In order to further examine the stability of $p^{*}$ and $q^{*}$, a specific set of contract values satisfying the constraints (1) and (2) are set, shown in Table 4, and yielding the payoff matrix shown in Table 5.

Table 4. An example: contract values.

\begin{tabular}{cccc}
\hline Parameter & $V_{1}$ & $L_{1}$ & $D_{1}$ \\
\hline Value & 2600 & 1050 & 2950 \\
\hline Parameter & $L_{2}$ & $V_{2}$ & $D_{2}$ \\
\hline Value & 150 & 2500 & 2550 \\
\hline
\end{tabular}

Table 5. An example: payoff matrix.

\begin{tabular}{ccc}
\hline \hline Project Owner & Hawk $\left(A_{\mathbf{1}}\right)$ & Dove $\left(A_{\mathbf{2}}\right)$ \\
\hline Project Contractor & $(2600-1050(1-\alpha),-2600-1050 \alpha)$ & $(2950-150(1-\beta),-2950-150 \beta)$ \\
\hline $\operatorname{Hawk}\left(B_{1}\right)$ & $(2500,-2500)$ & $(2550,-2550)$ \\
\hline $\operatorname{Dove}\left(B_{2}\right)$ & & \\
\hline
\end{tabular}

\subsection{Mixed Strategy Equilibrium under Stationary Conditions}

The first results are obtained by varying sharing ratios $\alpha$ and $\beta$. While $\beta$ slides between 0 and 1 freely, $\alpha$ is constrained by (2). $\beta$ and $\alpha$ are varied and the variables of interest are computed: the probabilities of the mixed strategy $p^{*}$ and $q^{*}$, as well as the expected revenues $U_{A}$ and $U_{B}$. A special case where $\beta=1$ is examined closely as it corresponds to the classical Hawk-Dove model where the only Nash Equilibrium is $\left(A_{2}, B_{1}\right)$. 


\subsection{1. $\beta=1$ : Classical Hawk-Dove Model}

When $\beta=1$, the contractor is exempted from sharing the additional cost and therefore has no loss for acting as a hawk. In this case, $\alpha$, ranging from 0.48 to 0.9 , due to constraints (2), is the only changing cost sharing ratio, completely affecting the expected probability and payoffs.

Figure 1 shows that with the increasing $\alpha, p^{*}$ decreases whereas $q^{*}$ grows. The larger ratio $\alpha$ makes the owner pay more on cost $L_{1}$ and consequently stimulates the owner's attitude towards acting as a hawk. Contrarily, the increase of $\alpha$ leaves the contractor paying less on $L_{1}$ and moving towards acting as a dove. A balance of strategy between the two parties is noted by the change of $\alpha$ : when one leans towards hawk, the other moves to dove and vice versa.
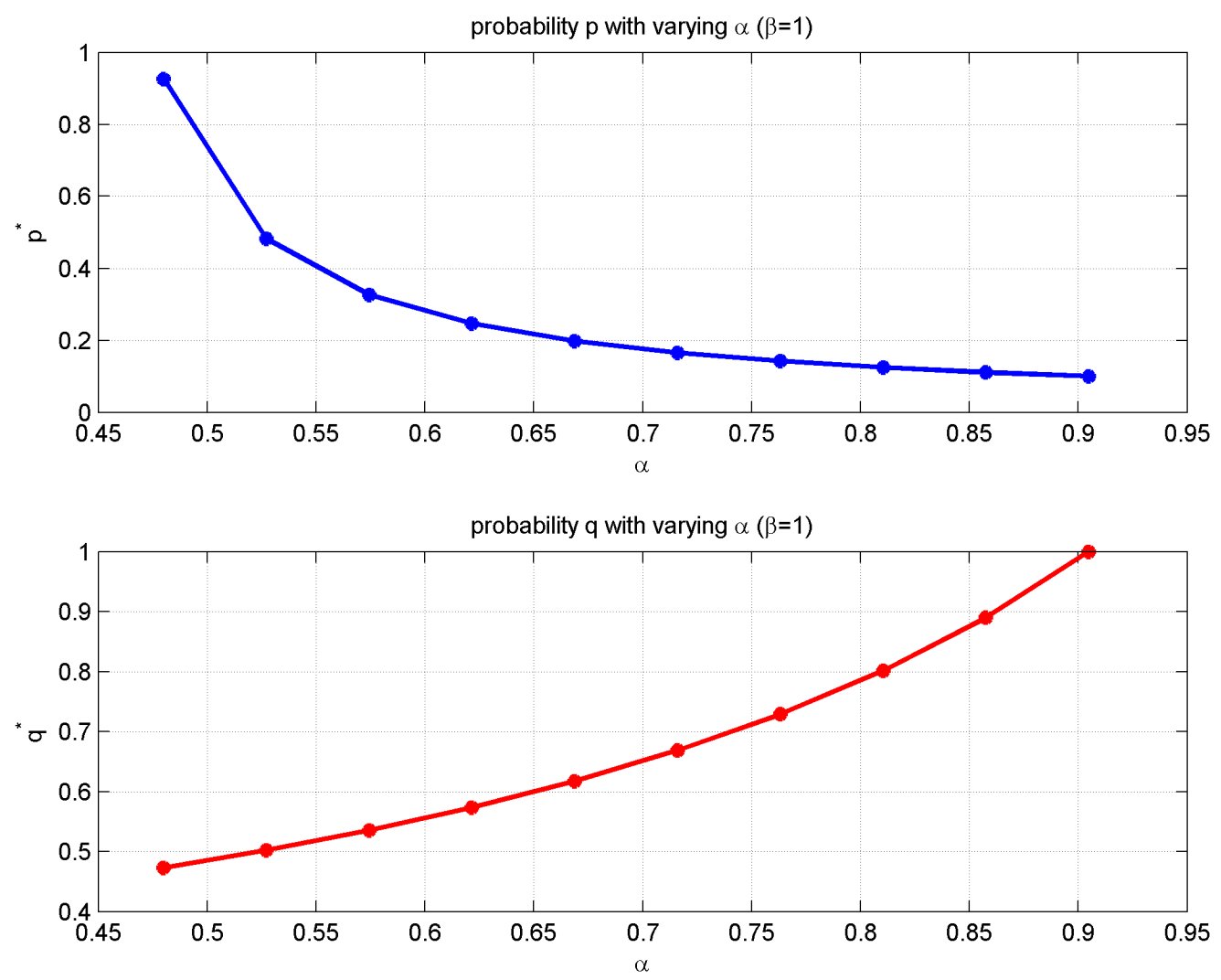

Figure 1. Expected probability of contractor $p^{*}$ and owner $q^{*}$. Ten equally spaced $\alpha$ between 0.48 and 0.9 .

Naturally, the hawks benefit more in resource allocation contests, and this perception also holds in this owner-contractor case (Figure 2). Both the contractor and the owner receive higher payment when acting as a hawk and the increase reaches saturation when $p^{*}$ and $q^{*}$ approach to 1. However, the reward of acting as a hawk is more substantial for the owner for smaller values of $\alpha$. For example, the increase from 0.48 (minimum $\alpha$ available) to 0.5 results in much larger positive payment difference (243.7) than the increase from 0.88 to 0.9 (maximum $\alpha$ available) which results in near-zero payment difference, as shown in Figure 2. A steep gradient is observed for owner's payment until $\alpha$ goes beyond 0.65 ; the change for the contractor counterpart is more uniform with considerably smaller magnitude. 
The decision on how to split the cost between owner and contractor, that is, the decision on selecting $\alpha$, then largely depends on some thresholds specifically determined by each party and their attitude. The confrontation penalty $L_{1}$ can be seen as a measure of risk since the higher $L_{1}$ reduces contingency and brings greater risk. A risk-seeking owner is less sensitive to the higher cost portion shared in $L_{1}$, in which case he can accept a smaller $\alpha$. For example, the steeper gradient change in payment with $\alpha$ in the range $0.55 \leq \alpha \leq 0.6$ indicates higher payment for the project owner compared with the amount when $\alpha \geq 0.65$, but may still fall into the acceptable range in eyes of a risk-seeking project owner. For a risk-averse owner, the case is quite the opposite, as a conservative owner is more than likely to be rigid in maintaining large $\alpha$, e.g., $\alpha \geq 0.75$. The contractor, in response, must adapt a different strategy in reflection to the penalty assessment.
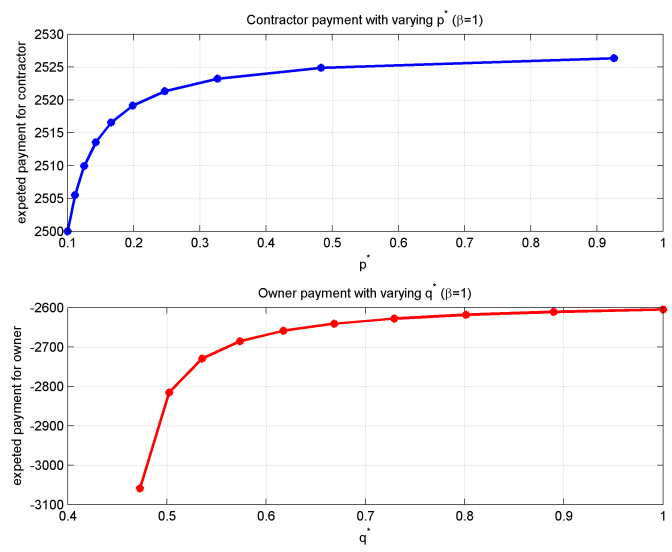

(a)
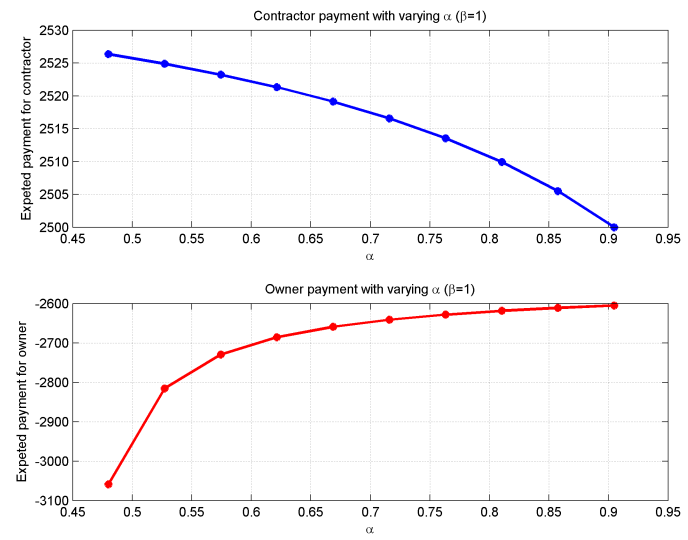

(b)

Figure 2. Expected payment of contractor $U_{B}$ and owner $U_{A}$. (a) payment with $p^{*}$ and $q^{*}$; (b) payment with $\alpha$.

In summary, when $\beta=1$, conclusions are made such that:

- The increase of $\alpha$ encourages the owner to act as a hawk while suppressing the contractor to act as a hawk.

- The higher the value of $\alpha$, the more likely is the transition from $\left(A_{2}, B_{1}\right)$ with small $\alpha$ to $\left(A_{1}, B_{2}\right)$ with large $\alpha$.

\subsubsection{Other Values of $\beta<1$}

Figure 3 gives a representation of how sharing ratios affect the expected probabilities.

Observations are made as following:

- $\quad p^{*}$ reaches 1 when $\beta$ approaches 1 with $\alpha$ at minima.

- With large $\alpha, p^{*}$ is close to 0 regardless of which value $\beta$ takes.

- $\quad q^{*}$ approaches 1 when both $\beta$ and $\alpha$ move towards 1 , indicating that $q^{*}$ is positively related to both $\beta$ and $\alpha$.

- Sharing ratios do impact on both $p^{*}$ and $q^{*}$ but the manipulation of $\alpha$ and $\beta$ cannot create scenario $\left(A_{1}, B_{1}\right)$ with high $p^{*}$ and $q^{*}$ : the former requires small $\alpha$ and the latter requires greater $\alpha$, where $\alpha$ clearly cannot meet both requirements.

The results presented in Figure 4 echo the conclusion drawn in the one-dimensional case $(\beta=1)$ discussed earlier. By acting as a hawk, the owner and the contractor gain higher benefit; the two-dimensional view indicates that $U_{A}$ and $U_{B}$ are both more responsive to the change of $q^{*}$ whereas higher $p^{*}$ does not give much gain to the payment. Figure 5 and Table 6 show how the 
combination of $\alpha$ and $\beta$ affects payment, in which case the best combination for the owner is high $\alpha$ with any $\beta$ between 0 to 0.8 and for the contractor is low $\alpha$ and $\beta$.
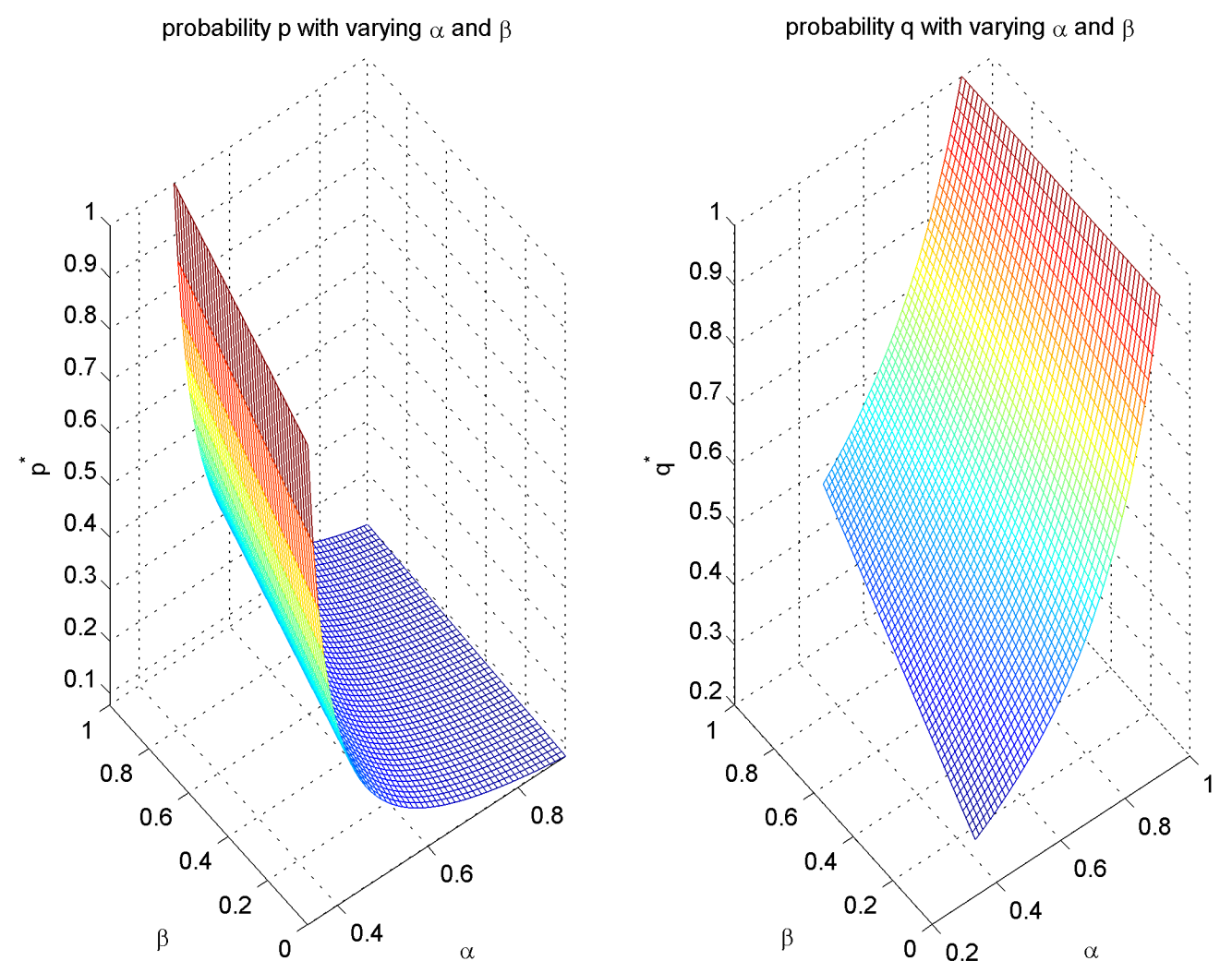

Figure 3. Expected probability $p$ and $q$ as a function of $\alpha$ and $\beta$.

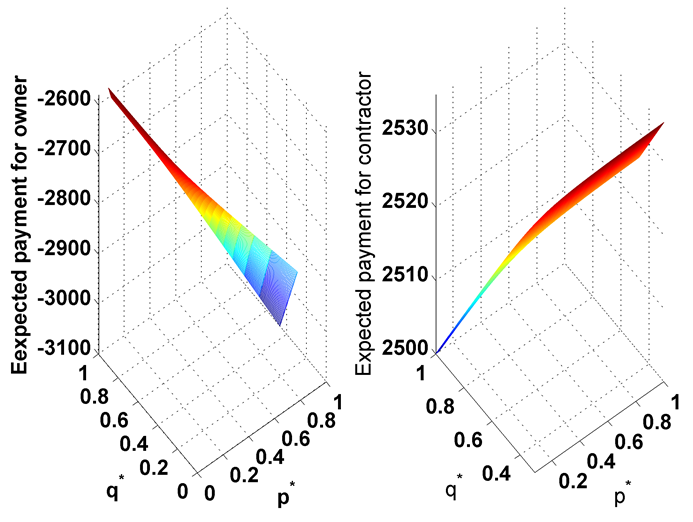

(a)
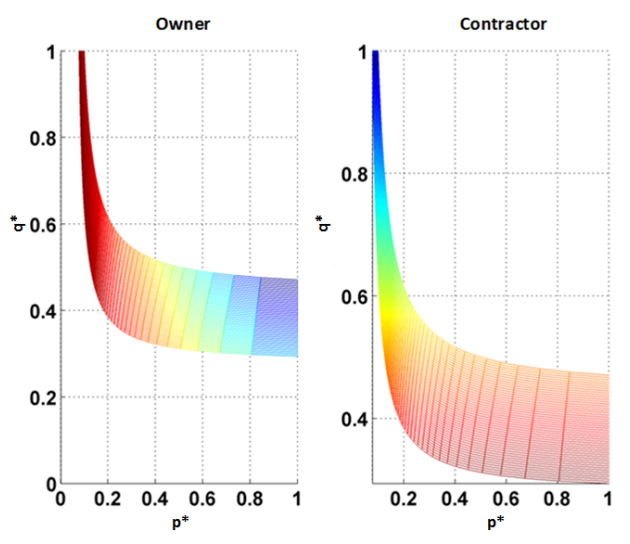

(b)

Figure 4. Expected payment $U_{A}$ and $U_{B}$ as a function of expected probability $p^{*}$ and $q^{*}$. (a) $3 \mathrm{~d}$ view; (b) $2 \mathrm{~d}$ view. 

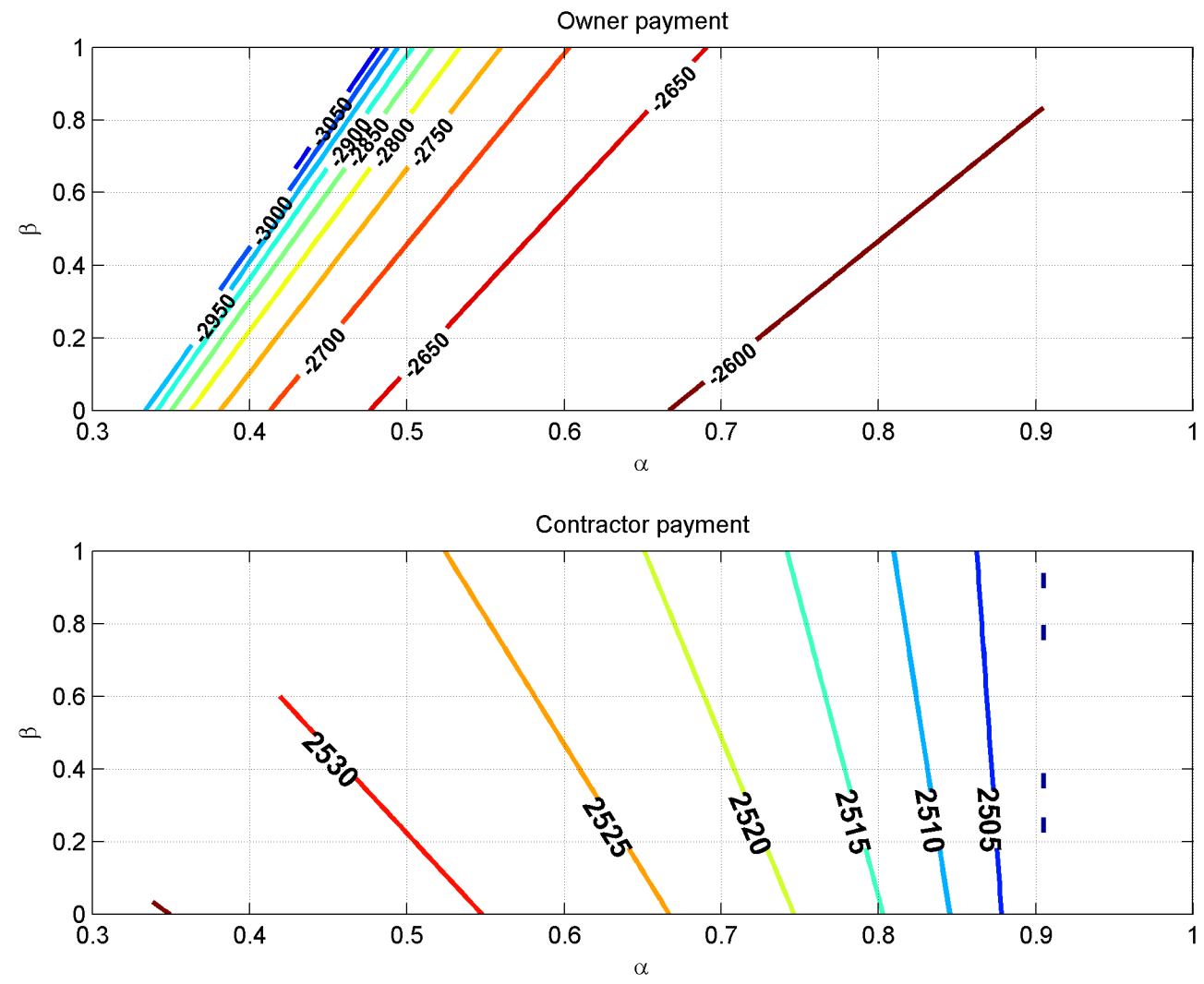

Figure 5. Expected payment $U_{A}$ and $U_{B}$ as a function of sharing ratios $\alpha$ and $\beta$.

Table 6. Best outcome.

\begin{tabular}{ccccc}
\hline Best Scenario & $\boldsymbol{\alpha}$ & $\boldsymbol{\beta}$ & $\boldsymbol{U}_{\boldsymbol{A}}$ & $\boldsymbol{U}_{\boldsymbol{B}}$ \\
\hline Owner & $0.65-0.9$ & $0-0.8$ & -2600 & 2505 \\
\hline Contractor & 0.35 & 0 & -2950 & 2535 \\
\hline
\end{tabular}

\subsection{Mixed Strategy Equilibrium under Noisy and Latent Conditions}

To evaluate the dynamic stability of the obtained equilibria, the expected probabilities are simulated over time using Vensim's System Dynamics Modelling (SDM) software [26]. The Vensim model is described in the Appendix A.

\subsubsection{Stability of Nash Equilibria}

The expected probabilities, $p$ and $q$, are plotted against time as shown in Figure 6. A time interval of 10 cycles (days) is set to capture the probability's dynamics in detail. It is observed that for all combinations of $\alpha$ and $\beta$, the expected probability for both the contractor and the owner converges to pure Nash equilibria fairly quickly. The convergence also requires opposing attitudes of the players: when $p_{0}$ is met, the other goes to $q_{1}$, and vice versa. 


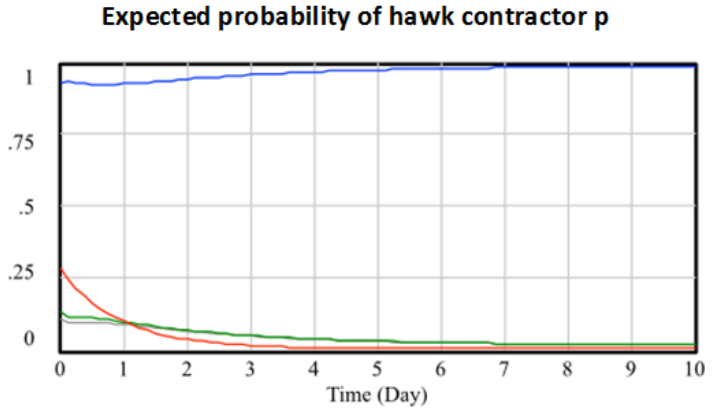

Expected probability of hawk owner q

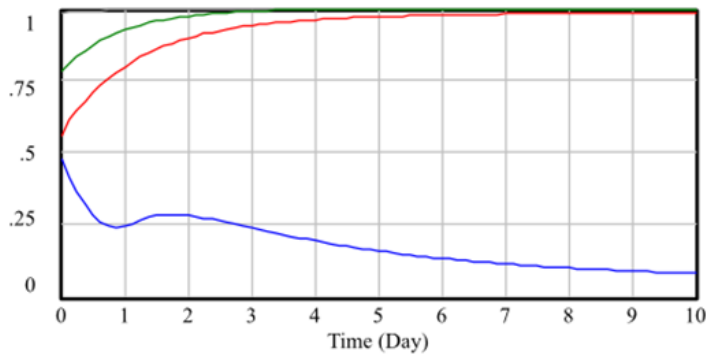
$\beta=1 \alpha=0.48$
$\beta=1 \alpha=0.6$
$\beta=1 \alpha=0.8$
$\beta=1 \alpha=0.9$

(a)
Expected probability of hawk contractor $p$

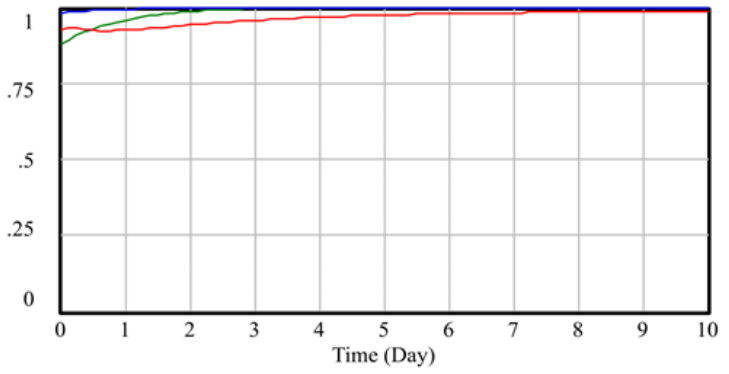

Expected probability of hawk owner q

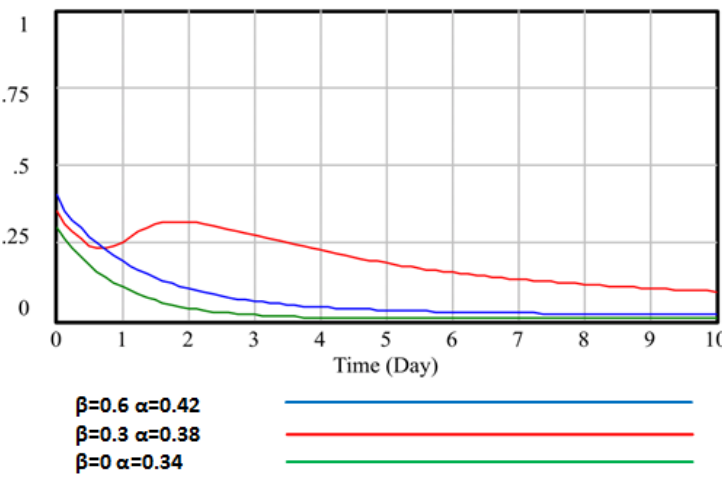

(b)

Figure 6. Original simulated expected probability. (a) $\beta=1$ and varying $\alpha$; (b) varying $\beta$ and $\alpha$.

Importantly, the simulations do not converge to the mixed strategy. Table 7 shows the corresponding mixed Nash equilibria for the $\alpha$ and $\beta$ pairs, simulation results of which are shown in Figure 6. Clearly, there are no observations of mixed Nash equilibria. This is consistent with the expectation that pure Nash equilibria are very stable and outperform the mixed strategy in the generalised Hawk-Dove model. It is then of interest to investigate which role mixed Nash equilibria play in this setting. The properties of the observed pure Nash equilibria shown in Figure 6 and the "hidden" mixed Nash equilibria are studied by changing initial conditions of variables while introducing noise and delay.

Table 7. Mixed strategy Nash equilibria.

\begin{tabular}{ccc}
\hline Tested Combination & $\boldsymbol{p}^{*}$ & $\boldsymbol{q}^{*}$ \\
\hline$\alpha=0.48 \beta=1$ & 0.926 & 0.473 \\
$\alpha=0.60 \beta=1$ & 0.278 & 0.556 \\
$\alpha=0.80 \beta=1$ & 0.128 & 0.784 \\
$\alpha=0.90 \beta=1$ & 0.101 & 0.987 \\
$\alpha=0.34 \beta=0$ & 0.877 & 0.297 \\
$\alpha=0.38 \beta=0.3$ & 0.926 & 0.349 \\
$\alpha=0.42 \beta=0.6$ & 0.980 & 0.400 \\
\hline
\end{tabular}


Phase portraits are constructed to further investigate the properties of the observed Nash equilibria. Four representative combinations of $\alpha$ and $\beta$ are considered, each with a distinct mixed strategy, summarised in Table 8. The initial conditions of variables, namely the initial numbers of hawk owner, hawk contractor, dovish owner, and dovish contractor, are changed in simulated runs to cover diverse combinations of scenarios. Each scenario corresponds to a quadrant in which three sets of expected probabilities ( $p$ and $q$ ) are selected, given the same combination of $\alpha$ and $\beta$, but with changing initial conditions specified according to Figure 7.

Table 8. Phase portrait combination with $p^{*}$ and $q^{*}$.

\begin{tabular}{ccc}
\hline Tested Combination & $\boldsymbol{p}^{*}$ & $\boldsymbol{q}^{*}$ \\
\hline$\alpha=0.48 \beta=1$ & 0.926 & 0.473 \\
\hline$\alpha=0.5 \beta=0.5$ & 0.3333 & 0.4333 \\
\hline$\alpha=0.7 \beta=0.5$ & 0.1388 & 0.6019 \\
\hline$\alpha=0.9 \beta=0.1$ & 0.0794 & 0.9815 \\
\hline
\end{tabular}

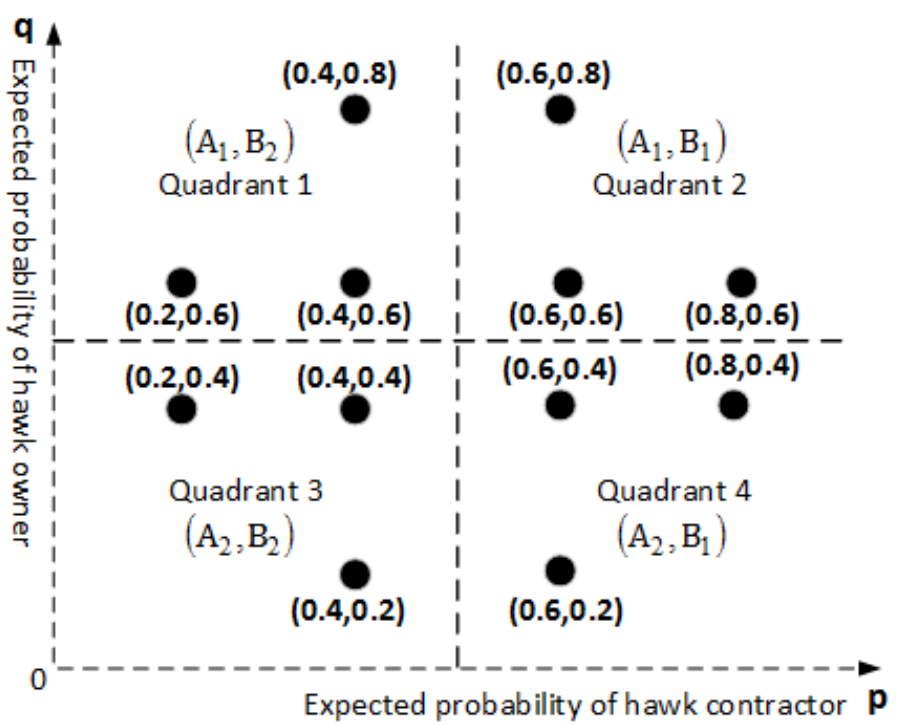

Figure 7. Phase portrait: initial conditions.

Figure 8 shows that the two pure Nash equilibria are stable with dynamics moving towards $\left(p_{0}, q_{1}\right)$ and $\left(p_{1}, q_{0}\right)$. Mixed Nash equilibrium is a saddle point as dynamics change direction around it, for all $\alpha$ and $\beta$ combinations, confirming the instability of the mixed Nash equilibrium in the generalised model.

The other two points, $\left(p_{0}, q_{0}\right)$ and $\left(p_{1}, q_{1}\right)$ are also unstable as the dynamics run away from these two extremes, indicating the instability of scenario $\left(A_{1}, B_{1}\right)$ and $\left(A_{2}, B_{2}\right)$.

The choice of $\alpha$ and $\beta$ does impact on which pure Nash equilibrium the dynamic settles at. With $\beta=1$, the increase of $\alpha$ shifts the equilibrium from $\left(A_{1}, B_{2}\right)$ to $\left(A_{2}, B_{1}\right)$. The scenario $\left(A_{2}, B_{1}\right)$ is also more stable when the costs are shared equally $(\beta=0.5, \alpha=0.5)$ or when $\beta$ is small $(\beta=0.1$, $\alpha=0.9$ ). In summary, it is confirmed that the mixed Nash equilibrium is an unstable saddle point as expected, and the introduction of $\alpha$ and $\beta$ alters the dynamics on pure Nash equilibria, however it does not challenge the dominance of these pure equilibria. 


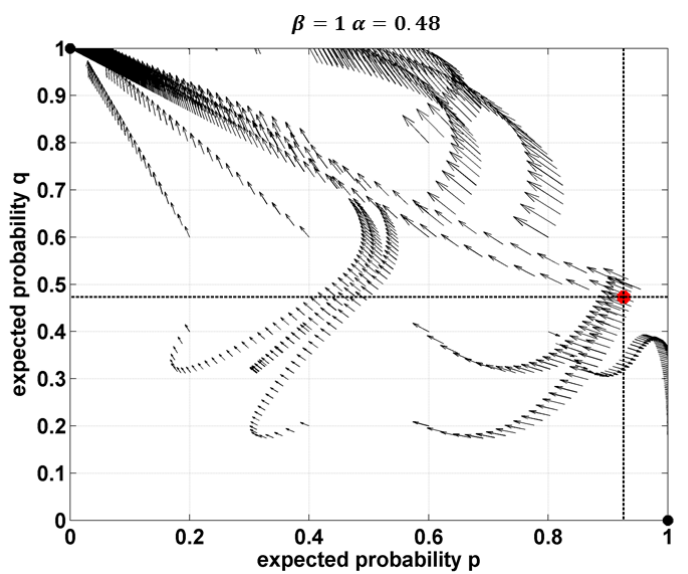

(a)

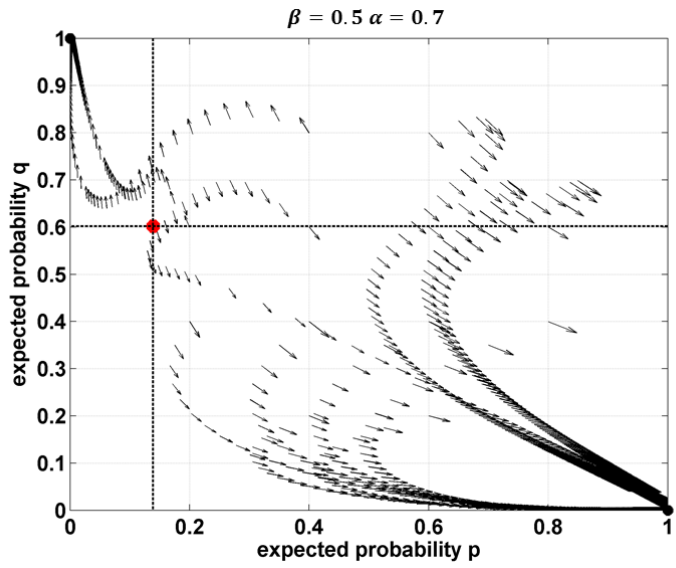

(c)

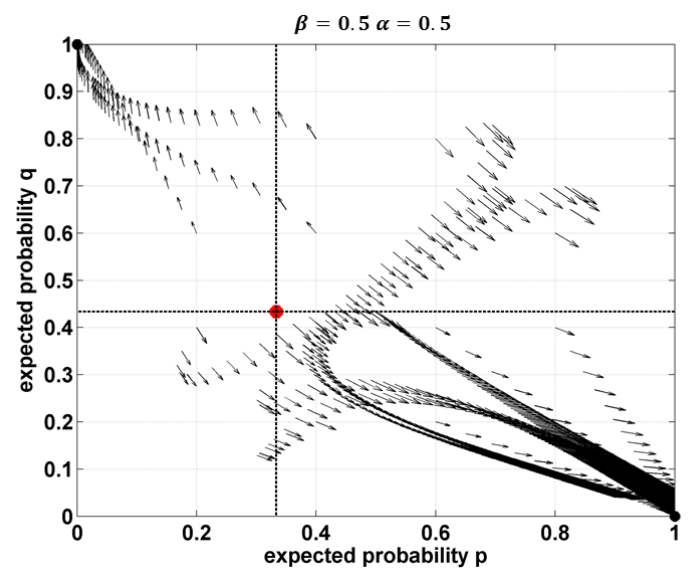

(b)

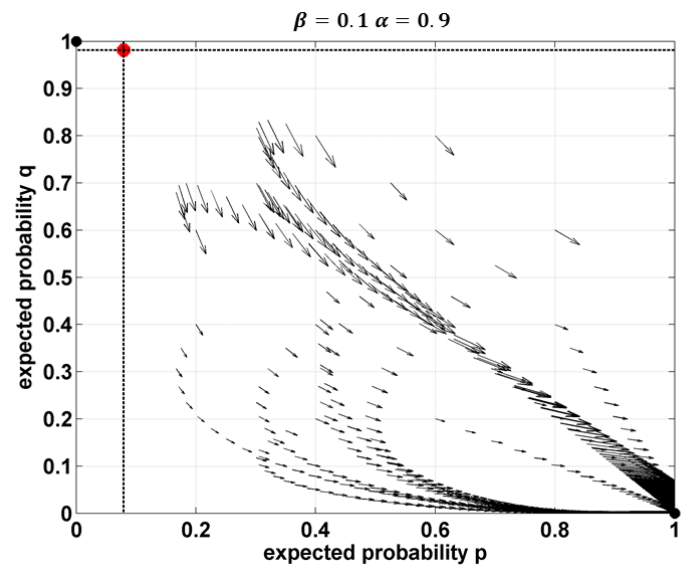

(d)

Figure 8. Phase portrait: mixed combination. (a) $\alpha=0.48 \beta=1$; (b) $\alpha=0.5 \beta=0.5$; (c) $\alpha=0.7 \beta=0.5$; (d) $\alpha=0.9 \beta=0.1$.

\subsubsection{Noise and Delay}

The players may receive information about the numbers of hawk and dove opponents with a delay and with noise, as described in the Appendix A.

To investigate the stability of the Nash equilibria under the noisy and latent conditions, evaluation of the dynamics for a range of combination of $\alpha$ and $\beta$ is made, observing the following (Figure 9):

- Pure Nash equilibria retain their robustness, and the combination of $\alpha$ and $\beta$ do not affect the resultant expected probability.

- The addition of noise and delay postpones but does not challenge the convergence to pure Nash equilibria.

- Noise creates noticeable oscillations but does not have a lasting impact once it is removed (in this case, after 200 days).

- The mixed Nash equilibrium, $\left(p^{*}, q^{*}\right)$, is not attained.

- The combination of $\alpha$ and $\beta$, as shown earlier, determines whether the expected probability converges to 0 or 1 . 

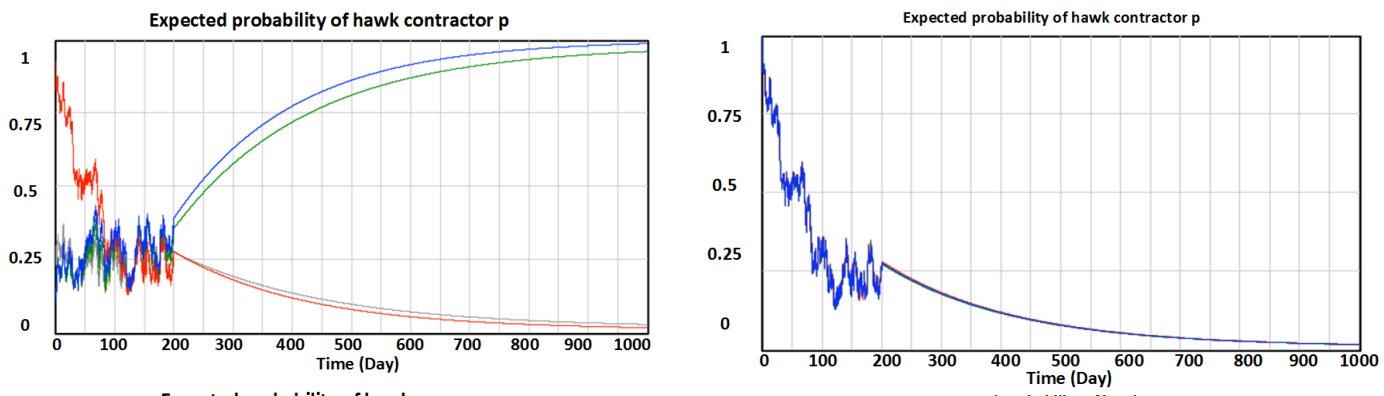

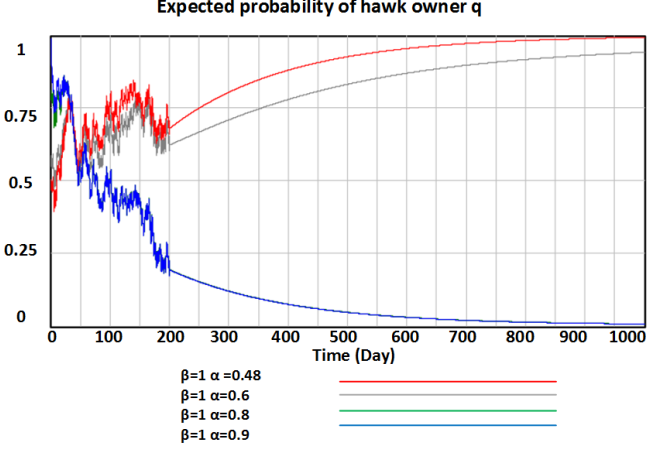

(a)

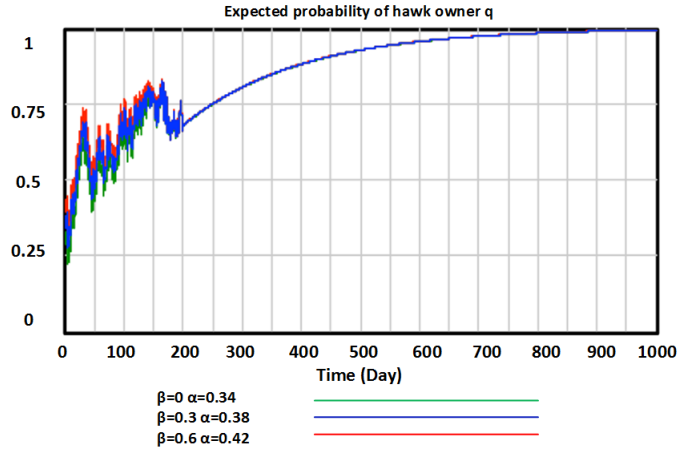

(b)

Figure 9. Expected probability with varying $\alpha$ and $\beta$. (a) $\beta=1$; (b) varying $\alpha$ and $\beta$.

Figure 10 confirms these observations for different values of noise and delay, taking case $\beta=1$ and $\alpha=0.48$ as an example. By adding noise and delay, the overall dynamic is not influenced: the mixed strategy remains the saddle point and pure Nash equilibria are robust.
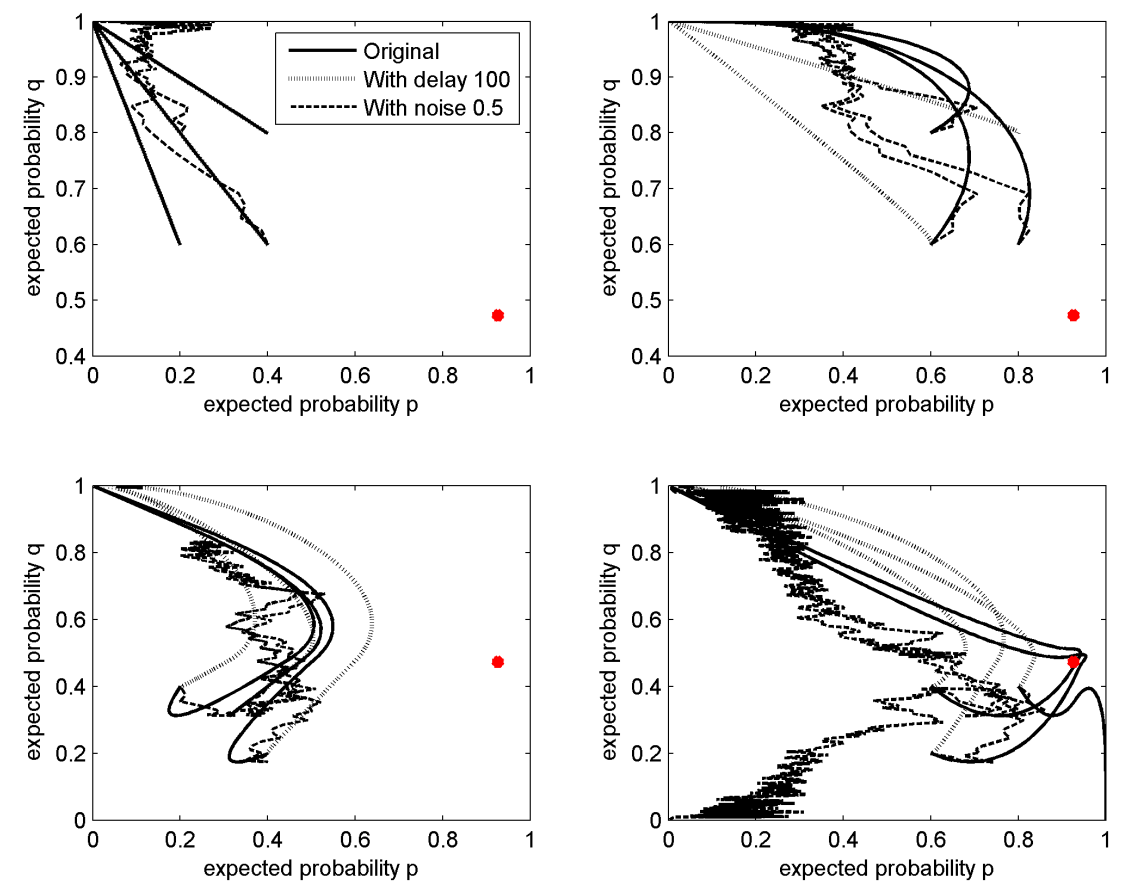

Figure 10. Phase portrait: delay and noise under different initial conditions. (top left) $\left(A_{1}, B_{2}\right)$; (top right) $\left(A_{1}, B_{1}\right)$; (bottom left) $\left(A_{2}, B_{2}\right)$; (bottom right) $\left(A_{2}, B_{1}\right)$. 


\section{Application in Context of Project Management}

The obtained results confirmed that only the pure Nash equilibria are stable when two parties adapt different strategies; therefore, only a confrontational balance between the owner and the contractor attitudes can achieve the optimal benefit.

Cost sharing ratios which may vary across cases are the key introduction leading to the generalisation of Hawk-Dove model; these ratios, once adopted by the other party, can in fact also serve as some indicators usable by project managers in anticipation of the attitudes of the other participants. The choice of those ratios may depend on practical factors that project managers consider: some are assumed knowledge, such as specific commonly perceived rules in a particular industry; some are specifically tailored to the organisational and individual level, such as the organisation's tolerance towards risks and the course of negotiation, and project managers' personal attitude to conflicts triggered by economic incentives, fear and uncertainty [27]. The level of trust also has a role in deciding these ratios. If participants focus on short-sighted benefits, the opportunity to obtaining maximum gain is most paramount; if participants lay their visions ahead for long-term benefits, the pay-off can be adjusted for a trust-based relationship [28]. As a result, by using the generalised model, project managers may gain insights into the strategy adaptation, and more importantly, understand the reasons leading to aggression or co-operation.

An earlier qualitative study showed that the adaptation of attitude has stimuli which can be tracked down to corporate or industry nature, or even deeper, to cultural influences [29]. Project managers can take these factors into consideration when deciding on sharing ratios. Though the model generalises stakeholder conflicts between the owner and the contractor, the framework holds for most stakeholders who have clashing interests and therefore can be applied to a wide range of scenarios with no limitation on the project's background.

\section{Conclusions}

Game theory can be described as the "conflict and co-operation analysis" [4], providing much needed answers to conflict and negotiation management. It has been widely applied in natural and social sciences, but its application in project management has not gained much prevalence [30].

In this paper, a generalised Hawk-Dove model is introduced to simulate the dynamics of strategy adaptation between two parties: the owner and the contractor. The model includes cost sharing ratios, studying their role and impact on strategy adaptation.

The results are verified in three stages: analytical solutions are derived for the generalised model, followed by simulation of stationary and dynamic behaviour. It is found that pure Nash equilibria are stable, as expected, while the mixed strategy is a saddle point with unstable dynamics.

Confrontational practice between the project owner and the contractors is also noted, as the optimal case occurs when one acts as a hawk and the other plays as a dove, and vice versa. The prediction of a specific confrontational strategy is not easily achievable, and so cost sharing ratios are considered to simplify decision-making. When the project contractor steps up acting as a hawk, taking the strategy $B_{1}$, the additional efforts in the communication and negotiation process produce financial costs to be shared between the two parties, shown as $L_{1}$ when the project owner acts as a hawk $\left(A_{1}\right)$ and $L_{2}$ when the project owner acts as a dove $\left(A_{2}\right)$. A hawk project owner would share the penalty $L_{1}$ with the hawk contractor via cost sharing ratio $\alpha$ while a dovish owner's share of cost in $L_{2}$ is manipulated by $\beta$. It is found that although the introduction of $\alpha$ and $\beta$ does not challenge the general convergence to a pure Nash equilibrium, their combination drives the destination of the pure Nash equilibrium, in which case either the owner favours large $\alpha$ with any $\beta$ in the allowed range, or the contractor leans towards small $\alpha$ and $\beta$.

This study may also apply to other roles of project participants engaged in a conflict of interest. The generic feature of the constructed model fits into an array of projects and the scope can be further expanded by including more than two players, unveiling the possibility of incorporating more sharing ratios, and leading to different Nash equilibria. Though the case with multiple players is not explored 
in this paper, future research in this direction may prove fruitful, expanding the significance of game theory applications in project management.

Author Contributions: S.L.C and M.P conceived and designed the methodology; S.L.C performed the analytical and computational anlysis; S.L.C and M.P wrote the paper. These authors contributed equally to this work.

Conflicts of Interest: The authors declare no conflict of interest.

\section{Appendix A}

A Vensim model is constructed to reflect the strategy adaptation of both players. Figure A1 shows the model, in which stock variables, shown in boxes, denote the expected probabilities, the historical accumulation of the number of hawks and doves for both players. The probabilities are computed as ratios of the corresponding numbers of hawk and dove players of each type, similar to the SDM model developed by [31]. All payment variables are set as constants, as well as the noise and delay (delay in $p$, delay in $q$, and noise) which feed into the flow rate variables (change in $p$ and change in $q$ ), and ultimately into the expected probabilities.

The noise is simulated as a set of randomly generated numbers ( $r a n d p$, and rand $q$ ) within defined boundaries (noise) and time steps. The simulation is carried out over 1000 days under Euler integration method with time step of 0.125 days.

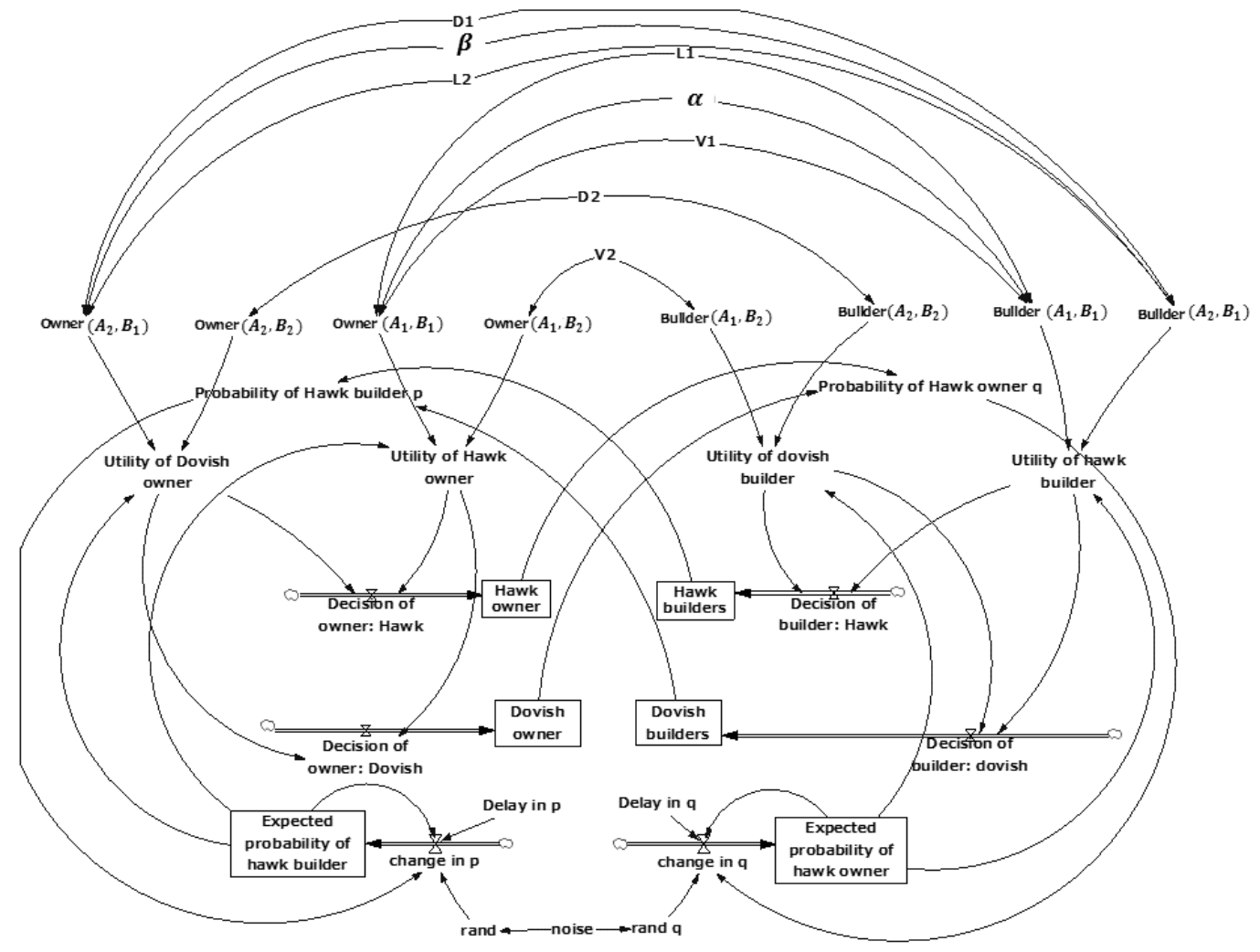

Figure A1. Vensim model. 


\section{References}

1. Project Management Institute (PMI). (Ed.) A Guide to the Project Management Body of Knowledge (PMBOK Guide); PMI, Inc.: Newtown Square, PA, USA, 2013.

2. Svejvig, P.; Anderson, P. Rethinking project management: A structured literature review with a critical look at the brave new world. Int. J. Proj. Manag. 2015, 33, 278-290.

3. Khanzadi, M.; Eshtehardian, E.; Chalekaee, A. A game theory approach for optimum strategy of the owner and contractor in delayed projects. J. Civ. Eng. Manag. 2016, 22, 1066-1077.

4. Myerson, R. Game Theory: Analysis of Conflict; Harvard University Press: Cambridge, MA, USA, 1991; pp. 2-3.

5. Curiel, I. Project management games. Int. Game Theory Rev. 2011, 13, 281-300.

6. Medda, F. Game theory approach for the allocation of risk in transport public private partnerships. Int. J. Proj. Manag. 2007, 25, 213-218.

7. Ho, S. Model for financial renegotiation in Public-Private Partnership projects and its policy implications: Game theoretic view. J. Constr. Eng. Manag. 2006, 132, 678-688.

8. Tserng, H.; Ho, S.; Chou, J.; Lin, C. Proactive measures of governmental debt guarantees to facilitate Public-Private Partnerships project. J. Civ. Eng. Manag. 2014, 20, 548-560.

9. Lv, J.; Ye,G.; Liu, W.; Shen, L.; Wang, L. Alternative model for determining the optimal concession period in managing BOT transportation projects. J. Manag. Eng. 2013, 31, 04014066.

10. Chen, T.; Lin, Y.; Wang, L. The analysis of BOT strategies based on game theory-Case study on Taiwan's high speed railways project. J. Civ. Eng. Manag. 2012, 18, 662-674.

11. Smith, J.M.; Price, G. The logic of animal conflict. Nature 1973, 246, 15-18.

12. Jones, J. Evolutionary Game Theory. Oneline Teaching Notes from Stanford University, 2008. Available online: https://web.stanford.edu/ jhj1/teachingdocs/Jones-ess-notes.pdf (accessed on 24 September 2017).

13. Opera, R.; Henwood, K.; Friedman, D. Separating the Hawks from the Doves: Evidence from continuous time laboratory games. J. Econ. Theory 2011, 146, 2206-2225.

14. Smith, J.; Parker, G.A. The logic of asymmetric contests. Anim. Behav. 1976, 24, 159-175.

15. Cressman, R. Evolutionary stability for two-stage hawk-dove games. Rocky Mt. J. Math. 1995, 25, $145-155$.

16. Hammerstein, P. The role of asymmetries in animal contests. Anim. Behav. 1981, 29, 193-205.

17. Kim, Y. Status signaling games in animal contests. J. Theor. Biol. 1995, 176, 221-231.

18. Attanasi, G.; García-Gallego, A.; Georgantzís, N.; Montesano, A. Environmental agreements as a Hawk-Dove game with confirmed proposals. Environ. Econ. 2012, 3, 35-42.

19. Attanasi, G.; García-Gallego, A.; Georgantzís, N.; Montesano, A. Bargaining over strategies of non-cooperative games. Games 2015, 6, 273-298.

20. Yang, Y.; Wang, M. Analysis on the interests of construction parties in project management model based on the Game Theory. In Proceedings of the 2009 Chinese Control and Decision Conference (CCDC), Guilin, China, 17-19 June 2009.

21. Ding, J. A study of construction project conflict management based on evolutionary game theory. In Modeling Risk Management in Sustainable Construction; Wu, D., Ed.; Springer: Berlin, Germany, 2011; pp. 321-326.

22. Zhang, G.; Gao, Y. An evolutioevol game model for the risk management cooperation among the project participants. In Modelling Risk Management in Sustainable Construction; Springer: Berlin, Germany, 2011; pp. 153-159.

23. Spiess, W. Conflict Prevention in Project Management: Strategies, Methods, Checlists and Case Studies; Springer: Berlin, Germany, 2008; p. 69.

24. Hofbauer, J.; Sigmund, K. Evolutionary game dynamics. Bull. Am. Math. Soc. 2003, 40, 479-519.

25. Houston, A.; McNamara, J. Evolutionarily stable strategies in a repeated hawk-dove game. Behav. Ecol. 1991, 2, 219-227.

26. Ventana Systems, Inc. User Guide_Vensim Introduction E Tutorial; Ventana Systems, Inc.: Harvard, MA, USA, 1989-2012.

27. Caldara, M.; McBride, M.; McCarter, M.; Sheremeta, R. A study of triggers of conflicts and emotional reactions. Games 2017, 8, 21. 
28. Goméz-Miñambres, J.; Schniter, E. Emotions and behaviour regulation in decision dilemmas. Games 2017, 8, 22.

29. Cheung, S.; Yiu, T.; Chiu, O. The aggressive-cooperative drivers of construction contracting. Int. J. Proj. Manag. 2008, 27, 727-735.

30. Barough, A.; Shoubi, M.; Skardi, M. Application of Game Theory Approach in solving the construction project conflicts. In Proceedings of the 8th International Strategic Management Conference, Barcelona, Spain, 21-23 June 2012.

31. Kim, D.; Kim, D. A system dynamics model for a mixed-strategy game between police and driver. Syst. Dyn. Rev. 1997, 13, 33-52.

(C) 2017 by the authors. Licensee MDPI, Basel, Switzerland. This article is an open access article distributed under the terms and conditions of the Creative Commons Attribution (CC BY) license (http://creativecommons.org/licenses/by/4.0/). 